\title{
The expression and function of TRPV4 channels in primate retinal ganglion cells and bipolar cells
}

Fan Gao ${ }^{1}$, Zhuo Yang ${ }^{1}$, Roy A. Jacoby ${ }^{1}$, Samuel M. Wu' and Ji-Jie Pang ${ }^{1}$

\begin{abstract}
The transient receptor potential vanilloid 4 (TRPV4) channel may be opened by mechanical stimuli to mediate $\mathrm{Ca}^{2+}$ and $\mathrm{Na}^{+}$influxes, and it has been suggested to mediate glaucoma retinopathy. However, it has been mostly unclear how TRPV4 activities affect the function of primate retinal ganglion cells (RGCs). We studied RGCs and bipolar cells (BCs) in the peripheral retina of the old-world primate using whole-cell current-clamp and voltage-clamp recordings, immunomarkers and confocal microscopy. RGCs were distinguished from displaced amacrine cells (ACs) by the absence of GABA and glycine immunoreactivity and possession of an axon and a large soma in the RGC layer. Strong TRPV4 signal was concentrated in medium to large somas of RGCs, and some TRPV4 signal was found in BCs (including PKCa-positive rod BCs), as well as the end feet, soma and outer processes of Müller cells. TRPV4 immunoreactivity quantified by the pixel intensity histogram revealed a high-intensity component for the plexiform layers, a lowintensity component for the soma layers of ACs and Müller cells, and both components in the soma layers of RGCs and BCs. In large RGCs, TRPV4 agonists 4a-phorbol 12,13 didecanoate (4aPDD) and GSK1016790A reversibly enhanced the spontaneous firing and shortened the delay of voltage-gated $\mathrm{Na}^{+}$(Nav) currents under current-clamp conditions, and under voltage-clamp conditions, 4aPDD largely reversibly increased the amplitude and frequency of spontaneous excitatory postsynaptic currents. In BCs, changes in the membrane tension induced by either applying pressure or releasing the pressure both activated a transient cation current, which reversed at $\sim-10 \mathrm{mV}$ and was enhanced by heating from $24^{\circ} \mathrm{C}$ to $30^{\circ} \mathrm{C}$. The pressure for the half-maximal effect was $\sim 18 \mathrm{mmHg}$. These data indicate that functional TRPV4 channels are variably expressed in primate RGCs and BCs, possibly contributing to pressure-related changes in RGCs in glaucoma.
\end{abstract}

\section{Introduction}

Glaucoma is a retinal disease, characterized by the axon injury and soma loss of retinal ganglion cells (RGCs). It is a leading cause of blindness worldwide ${ }^{1}$, but its exact pathological mechanism is still uncertain. Glaucoma is involved with multiple risk factors, such as biochemical cascades, genetic defects, apoptotic cell death, glutamate excitotoxicity, free radical injury, mitochondria damage, glial activation, etc., while the elevation of the intraocular

Correspondence: Ji-Jie Pang (jpang@bcm.edu)

'Department of Ophthalmology, Baylor College of Medicine, One Baylor Plaza, NC 205, Houston, TX 77030, USA

Edited by A. Verkhratsky pressure (IOP) (either the mean level or the fluctuation) $)^{2,3}$ is a significant risk factor ${ }^{1}$. Although RGCs are intrinsically susceptible to IOP elevation, how elevated IOP damages RGCs has been debated. Neurons express ion channels in the plasma membrane, and some channels can be directly opened by force ${ }^{4}$ and are known as mechano-gated or mechanosensitive channels (MSCs). MSCs have been found in multiple types of retinal cells and postulated to contribute to glaucoma retinopathy ${ }^{5,6}$, one of which is the transient receptor potential channel (TRP) vanilloid 4 (TRPV4) $)^{7,8}$. Mutations in TRPV4 have been linked to axonal neuropathies in patients ${ }^{9}$, but the

\section{(c) The Author(s) 2019}

(c) Open Access This article is licensed under a Creative Commons Attribution 4.0 International License, which permits use, sharing, adaptation, distribution and reproduction cc) in any medium or format, as long as you give appropriate credit to the original author(s) and the source, provide a link to the Creative Commons license, and indicate if changes were made. The images or other third party material in this article are included in the article's Creative Commons license, unless indicated otherwise in a credit line to the material. If material is not included in the article's Creative Commons license and your intended use is not permitted by statutory regulation or exceeds the permitted use, you will need to obtain permission directly from the copyright holder. To view a copy of this license, visit http://creativecommons.org/licenses/by/4.0/. 
function of TRPV4 in the primate retina has not been studied.

MSCs are important for eukaryotic cells to balance osmotic and mechanical pressures across the plasma membrane. Although MSCs are typically adaptive to sustained mechanical stimuli ${ }^{10}$, TRPs do respond to transient signals (e.g. changes in mechanical force and light intensity). Circulation of the aqueous humor acts to stabilize IOP, yet, IOP still fluctuates to some extent. It shows 2-3 pulses per second in primates under physiological conditions ${ }^{11}$, and the amplitude is larger under higher IOP levels. In addition, retinal neurons may be stretched in childhood glaucoma (also known as buphthalmos). In chronic glaucoma, the optic disc cupping may stretch RGC axons there (e.g. for $\sim 70-646 \mu \mathrm{m}$, derived from ${ }^{12,13}$ ). Therefore, MSCs can possibly be activated by both physiological and pathological IOP. Thus, it is essential to determine the effect of TRPV4 activation on activities of RGCs and other retinal neurons.

TRPs include seven subfamilies, namely TRPC (canonical), TRPV, TRPM (melastatin), TRPN (NOMPC), TRPA (ANKTM1), TRPP (polycystin) and TRPML (mucolipin) $)^{14,15}$. TRPs share the common feature of six transmembrane domains, various degrees of sequence similarity, and permeability to cations. The cation permeability $(\mathrm{P})$ is usually indicated by the $\mathrm{PCa} / \mathrm{PNa}$ ratio, which for TRPV1-6 (the six members of TRPV subfamily) is 3.8-9.6, 3, 2.8, 6, $>100$ and $>100$, respectively. The cation conductance allows TRPs to mediate membrane depolarization and $\mathrm{Ca}^{2+}$ influxes, which are known to be associated with neuronal excitotoxity. TRPs are variably modulated by temperature, osmolality, membrane tension, phorbol esters and Gprotein-mediated regulation ${ }^{16}$, which allows identification of TRPV4. TRPV4 opens by pressure ${ }^{17}$, membrane stretch $^{18}$, warm temperature and specific pharmacological agonists like GSK1016790A (GSK) and 4 $\alpha \mathrm{PDD}^{15,19}$. TRPV4, TRPM8, and TRPV3 work at similar temperatures. However, TRPV4 is a warm sensor activated at $27^{\circ} \mathrm{C}^{14,20}$, while TRPM8 is a cold sensor and TRPV3 is a heat sensor activated at $23-28^{\circ} \mathrm{C}$ and $\geq 33^{\circ} \mathrm{C}$, respectively. This study used the pressure sensitivity, thermosensitivity, specific pharmacological modulators, the reversal potential of TRPV4mediated currents and immunolabeling to identify TRPV4 channels in primate RGCs and BCs.

Recently, morphological studies in glaucoma models have indicated that RGCs lose excitatory synapses while the axons are not lost ${ }^{21}$, and a functional study ${ }^{22}$ showed that IOP elevation reduces RGC light sensitivity by disrupting BC-RGC and BC-AII amacrine cell (AC) synaptic signals prior to retinal histological changes. RGCs receive excitatory glutamatergic synapses from $\mathrm{BCs}^{23}$. The bwave of the electroretinogram (ERG) primarily reflects the function of BCs, and its amplitude and kinetics have showed changes in glaucoma retinas ${ }^{24}$ TRPV4 immunoreactivity has been observed in RGCs and the plexiform layers in the $\mathrm{rat}^{25}$ and porcine ${ }^{8}$ retinas. TRPV4 was located in mouse RGC dendrites, somas and axon bundles in the retina, optic nerve head and laminar region of the optic nerve, as well as in Müller cells ${ }^{7,26}$. TRPV4 immunoreactivity in the outer plexiform layer $(\mathrm{OPL})^{7,8}$ displayed a horizontal expression pattern, so neuronal processes there are to be excluded to express TRPV4.

The structure and function of the primate retina do not fully resemble other mammalian retinas. For instance, visual signals converge into RGCs in different ways ${ }^{27}$, and the function of TRPV4 has not been examined in primate RGCs and BCs before. This study provides morphological and physiological evidence for the expression of functional mechanosensitive TRPV4 in the primate retina. Our data indicate that both RGCs and BCs are mechanically sensitive.

\section{Materials and methods \\ Animals}

This work used isolated retinal tissues from both macaques (Macaca mulatta) and baboons (Papio cynocephalus anubis). All procedures were carried out in strict accordance with the recommendations in the Guide for the Care and Use of Laboratory Animals of the National Institutes of Health and ARVO Statement for the Use of Animals in Ophthalmic and Vision Research. Isolated retinas used in this study were from third-party sources. Eyes were enucleated in ambient light illumination within 10 minutes after the animal had been overdosed with sodium pentobarbital $(50-100 \mathrm{mg} / \mathrm{kg}$, IV) at the conclusion of experiments that did not involve the eyes. The enucleated eyes were hemisected and then transported to our laboratory in oxygenated Ames medium (Sigma, St. Louis, MO) at room temperature. Eyecups with attached retinas were incubated in oxygenated Ames medium for $3-5 \mathrm{~h}^{28}$ in room temperature in ambient light illumination before experiments. 16 retinas mostly from 7 to 14 year-old animals were tested, focusing on the midperipheral and peripheral retina. Retinas were cut into $3 \times 3 \mathrm{~mm}^{2}$ pieces, some of which were used for the immunocytochemistry and others for electrophysiological recording and the morphological study of recorded cells. The pieces for recording light responses were incubated in darkness for $1-2 \mathrm{~h}$ before the experiment. Each drug was tested two to three times for each cell to confirm the effect, and the current and voltage responses of a cell to a stimulus or drug were repetitively recorded for at least three trials.

\section{Whole-cell current-clamp, voltage-clamp, and loose patch recording}

We recorded spontaneous action potentials under both loose-patch and current-clamp modes from 15 retinas. 
Only the peripheral retina ( $>7 \mathrm{~mm}$ away from the fovea) was selected for the recording, and each cell was recorded from a different retina. We also performed a systematic voltage-clamp analysis on spontaneous postsynaptic currents (PSCs) and light-evoked currents in RGCs. The excitatory and inhibitory PSCs were separated by holding the membrane potential to the cation or chloride equilibrium potential $\left(\mathrm{E}_{\mathrm{C}}\right.$ and $\mathrm{E}_{\mathrm{Cl}}$, respectively), so that $\mathrm{BC}$ contributions to RGC light responses (cation currents, $\Delta \mathrm{I}_{\mathrm{C}}$, recorded at $\mathrm{E}_{\mathrm{Cl}} \approx-60 \mathrm{mV}$ ) and contributions of amacrine cells (ACs) to RGC light responses (chloride currents, $\Delta \mathrm{I}_{\mathrm{C}}$, recorded at $\mathrm{E}_{\mathrm{C}} \approx 0 \mathrm{mV}$ ) could be separately studied $^{29-31}$. This approach also allows us to separately record the effect of TRPV4 modulators on RGC spontaneous excitatory postsynaptic currents (sEPSCs, recorded at $\mathrm{E}_{\mathrm{Cl}}$ ) mediated by $\mathrm{BC}$ synapses ${ }^{29}$ and spontaneous inhibitory postsynaptic currents (sIPSCs, at $\mathrm{E}_{\mathrm{C}}$ ) mediated by $\mathrm{AC}$ synapses ${ }^{30,31}$. Another advantage of this approach is that individual RGCs can be filled with LY and/or NB during recording for the morphological identification of RGCs.

Whole-cell patch-clamp and loose-patch recordings of RGCs used flat-mounted retinal preparations. The sclera was removed, and the isolated retina was mounted to the bottom of the recording chamber with the RGC layer (GCL) up for recording. BCs were recorded from living retinal slices. A piece of the isolated retina was mounted to the bottom of the recording chamber and cut into 200-300- $\mu \mathrm{m}$-thick slices with a home-made slicer. Each slice was remounted by turning 90 degrees to reveal the layers of the retina for recording. The preparation of living retinal slices essentially followed previous publications ${ }^{22}$. $\mathrm{BCs}$ locating in the first soma row of the inner nuclear layer with vertical oval-shaped somas were recorded and confirmed to be BCs after recording by their typical bipolar morphology ${ }^{22}$ (also see below). Procedures for recording light responses were performed under infrared illumination with dual-unit Nitemare (BE Meyers, Redmond, WA) infrared scopes. Whole-cell patch-clamp and loose-patch recording essentially followed the procedures reported in previous publications ${ }^{22,32}$. Oxygenated Ames solution (adjusted to $\mathrm{pH} 7.3$ ) was introduced continuously to the recording chamber. A photostimulator was used to deliver light spots (of diameter $600-1200 \mu \mathrm{m}$ ) to the retina via the epi-illuminator of the microscope. The intensity of unattenuated $(\log \mathrm{I}=0) 500 \mathrm{~nm}$ light was $1.4 \times 10^{6}$ photons $\mu \mathrm{m}^{-2} \mathrm{~s}^{-1}$. Recordings were performed with an Axopatch 700B amplifier, a DigiData 1322A interface and pClamp software v9.2 (Axon Instruments, Foster City, CA). Recording pipettes had a tip diameter of $0.3-0.5 \mu \mathrm{m}$ and the tip resistance of $5-8 \mathrm{M} \Omega$, and they were filled with an internal solution containing $118 \mathrm{mM} \mathrm{K}$ gluconate, $10 \mathrm{KCl}, 10 \mathrm{mM}$ EGTA, $0.5 \mathrm{mM} \mathrm{CaCl}_{2}, 1 \mathrm{mM}$ $\mathrm{MgCl}_{2}, 4 \mathrm{mM}$ ATP, $0.3 \mathrm{mM}$ GTP, $10 \mathrm{mM}$ HEPEs, and
$0.08 \%$ LY (and/or 2\% of neurobiotin (NB), Vector Laboratories, Burlingame, $\mathrm{CA}$ ), adjusted to $\mathrm{pH} 7.2$ with $\mathrm{KOH}$. $\mathrm{E}_{\mathrm{Cl}}$, with this internal solution, was $-61 \mathrm{mV}$. For recording pressure-induced non-selective cation currents mediated by TRPs, $\mathrm{K}^{+}$in the internal solution was replaced by $\mathrm{Cs}^{+}{ }^{33}$ to block $\mathrm{K}^{+}$channels. The liquid junction potential at the tip of the patch electrode was compensated prior to seal formation with pClamp software. Drugs were dissolved in Ames mediums and applied in the bath. Specific TRPV4 agonists 4 $\alpha$-phorbol 12,13

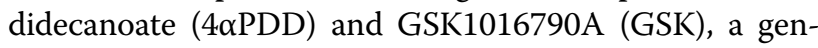
eral mechanosensitive channel blocker Ruthenium red (RR) (Tocris, Bristol, UK) ${ }^{34}$, as well as other chemicals, were purchased from Sigma-Aldrich unless stated otherwise.

A temperature control unit (TC 324B, Warner Instruments, CT) was used to control and monitor the temperature of the medium in the recording chamber. It was connected to the DigiData1322A to record the temperature of the medium. The medium was maintained at $34^{\circ} \mathrm{C}$ for experiments in RGCs. Cold Ames medium $\left(4^{\circ} \mathrm{C}\right)$ was heated to different temperatures by the control unit to test the effect on BCs.

Positive and negative pressure $(10-63 \mathrm{mmHg})$ steps were applied to cells during recording by altering the pressure inside the recording pipette after forming the giga-ohm seal (extracellularly) and after breaking through the membrane (intracellularly). The pressure was calibrated by a digital manometer DM8215 (Cole-Parmer, Vernon Hills, IL) with a resolution of $0.57 \mathrm{mmHg}^{35}$. In some well-studied mechano-gated channels ${ }^{36}$, the convex membrane deformation facilitates the opening of mechanosensitive channels. The current and voltage responses of the recorded cell to pressure steps were recorded simultaneously with the temperature signals with a temporal resolution of $1-10 \mathrm{kHz}$.

After recording, retinas with LY- and /or NB-filled cells were fixed, stained with Cy3-, Cy5-, or Alexa Fluor 488conjugated streptavidin (1:200, Jackson ImmunoResearch) and observed with confocal microscopes for the morphological identification of cell types. Then the flat-mount retinas with recorded RGCs were further sliced (see below) and observed again to accurately locate neuronal processes in the IPL ${ }^{32}$.

\section{Primary and secondary antibodies}

Polyclonal rabbit anti-TRPV4 (LS-C135, 1:200; LSA8583 1:200 and LS-C94498 1:100) ${ }^{7}$ was purchased from LifeSpan Biosciences, Inc (Seatle, WA). LS-C94498 was raised against a synthetic peptide from the cytoplasmic domain (aa100-150) of mouse TRPV4 conjugated to an immunogenic carrier protein. LS-A8583 targets a synthetic 20-amino acid peptide from the internal region of human TRPV4, and LS-C135 was 
raised against rat TRPV4 (Q9ERZ8, aa853-871, peptide immunogen sequence: CDGHQQGYAPKWRAEDAPL). In our hands, LS-C135 provided the best signal-to-noise ratio in the primate retina. The specificity of LS-A8583 and LS-C94498 for labeling retinal TRPV4 has been confirmed in TRPV4 knockout mice ${ }^{7}$, and LS-C135 and LS-A8583 provided similar labeling patterns (see Results). These data support the specificity of these antibodies. Other primary antibodies included in this study have also been used in previous reports, including polyclonal guinea pig anti-GABA (1:1000, AB175; Chemicon, Temecula, $\mathrm{CA})^{37}$ and rat anti-glycine antiserum (1:1000, a generous gift from Dr. David Pow, University of Queensland, Brisbane, QLD, Australia) ${ }^{38}$. Protein Kinase-C alpha (PKC $\alpha)$ is a classic marker for $\operatorname{rod} \mathrm{BCs}^{39}$. The anti-PKC $\alpha$ antibody from Sigma (P4334, 1:1000, rabbit, polyclonal) has been tested in immunoblotting in rat brain extract, and it recognized a heavy band at $76 \mathrm{kDa}$ and a very weak band at $40 \mathrm{kDa}$, while the predicted molecular weight of the PKC $\alpha$ was $76-93 \mathrm{kDa}$. The staining was specifically inhibited by PKC $\alpha$ immunizing peptide (659-672). The monoclonal anti-PKC $\alpha$ antibody from BD transduction (610107, Clone $3 / \mathrm{PKC} \alpha$ (RUO), 1:200, mouse) identified a single band at $82 \mathrm{kDa}$ from a rat cerebrum lysate. Monoclonal mouse antiglutamine synthetase (GS) (1: 1000, clone 6, BD Transduction Laboratories, Palo Alto, CA) was used to identify Müller cells ${ }^{40}$. The antibody was raised against the human glutamine synthetase aa $1-373$ and recognized a band at $\sim 45 \mathrm{kDa}$, consistent with the predicted molecular weight of GS.

The specificity of these primary antibodies has been demonstrated in the previous studies, and their staining patterns in our results were similar to the previous reports. Controls were also processed with blocking peptides or without primary antibodies. All controls did not show positive results.

\section{Immunocytochemistry}

Retinal tissues from 16 retinas were fixed with $4 \%$ paraformaldehyde in phosphate buffer $(\mathrm{pH}$ 7.4) for $1-2 \mathrm{~h}$ at $4{ }^{\circ} \mathrm{C}$. They were then blocked with $10 \%$ donkey serum (Jackson ImmunoResearch, West Grove, PA) in TBS ((D-PBS with $0.5 \%$ Triton X-100 (Sigma-Aldrich) and $0.1 \% \mathrm{NaN} 3$ (Sigma-Aldrich)) for $2 \mathrm{~h}$ at room temperature or at $4{ }^{\circ} \mathrm{C}$ overnight to reduce nonspecific labeling. A small piece of the retina was embedded in low gel-point agarose (Sigma-Aldrich) and trimmed into a $10 \times 10 \times 10 \mathrm{~mm}^{3}$ block. The block was glued onto a specimen chamber mounted on a vibratome (Pelco 102, 1000 Plus; Ted Pella, Inc., Redding, CA) and subsequently cut into $40-\mu \mathrm{m}$-thick vertical sections in PBS solution ${ }^{40}$. For staining, retinal tissues were incubated in primary antibodies in the presence of $3 \%$ donkey serum-
TBS for 3 to 5 days at $4{ }^{\circ} \mathrm{C}$. After several rinses, they were transferred into Cy3-, Cy5-, or Alexa Fluor 488conjugated streptavidin (1:200, Jackson ImmunoResearch), with Cy3- and/or Cy5-conjugated secondary antibodies (1:200, Jackson ImmunoResearch) and/or Alexa Fluor 488-conjugated secondary antibodies (1:200, Molecular Probes, Eugene, OR), in 3\% normal donkey serum-TBS solution at $4{ }^{\circ} \mathrm{C}$ overnight. A nuclear dye, TO-PRO-3 $(0.5 \mu \mathrm{L} / \mathrm{mL}$, Molecular Probes, Eugene, Oregon) was used with the secondary antibody to visualize nuclei in retinas. After extensive rinsing, retinal preparations were cover-slipped. Two small pieces of filter paper $(180-\mu \mathrm{m}$ thick, MF-membrane filters; Millipore, Billerica, MA) were mounted beside flatmount retinas to prevent them from being overflattened.

\section{Confocal microscopy}

Zeiss confocal microscopes (LSM 510 and LSM 800, Carl Zeiss, Germany) and imaging software were used for morphological observation. Recorded cells were observed with a 40× water immersion lens (for RGCs) and 40x and $60 \times$ oil lenses (all cells). A series of optical sections were made over each recorded cell, including the soma and all processes, for better morphological identification. The entire dendritic arbor was revealed by the $x-y$ view of the reconstructed 3D image of the cell. The dendritic ramification pattern in the inner plexiform layer (IPL) was revealed either in retinal slices or by the $y-z$ and $x-z$ views of the reconstructed 3D image of the recorded cell. Previously established methods were used to survey RGC density in the flat-mounted retinas ${ }^{40,41}$ and the soma size $^{40}$ of TRPV4-positive RGCs. Confocal micrographs were further processed with Photoshop (Adobe Systems Incorporated, San Jose, CA) software, typically by enhancing the contrast and selecting color channels with better visibility for light-adapted human eyes. In this paper, some confocal micrographs are presented with a white background, which was achieved simply by inverting the image of a black background with Photoshop software. The level at which dendritic processes stratified in the IPL was described by the distance from the processes to the distal margin (0\%) of the IPL. RGCs were counted in flat-mount retinas with confocal and Photoshop software. Immunolabeled retinas were generally examined with a vertical resolution of $0.4-1.2 \mu \mathrm{m}$ under regular line-scan and frame-scan modes and further examined with confocal Airyscan protocol and software with a pixel size of $30 \mathrm{~nm}$. The Airyscan images were displayed by the 3D surface profile reconstructed from a series of optical sections obtained with a step of $180 \mathrm{~nm}$. The immunoreactivity was quantified by the pixel intensity histogram in original confocal images without any modification. 

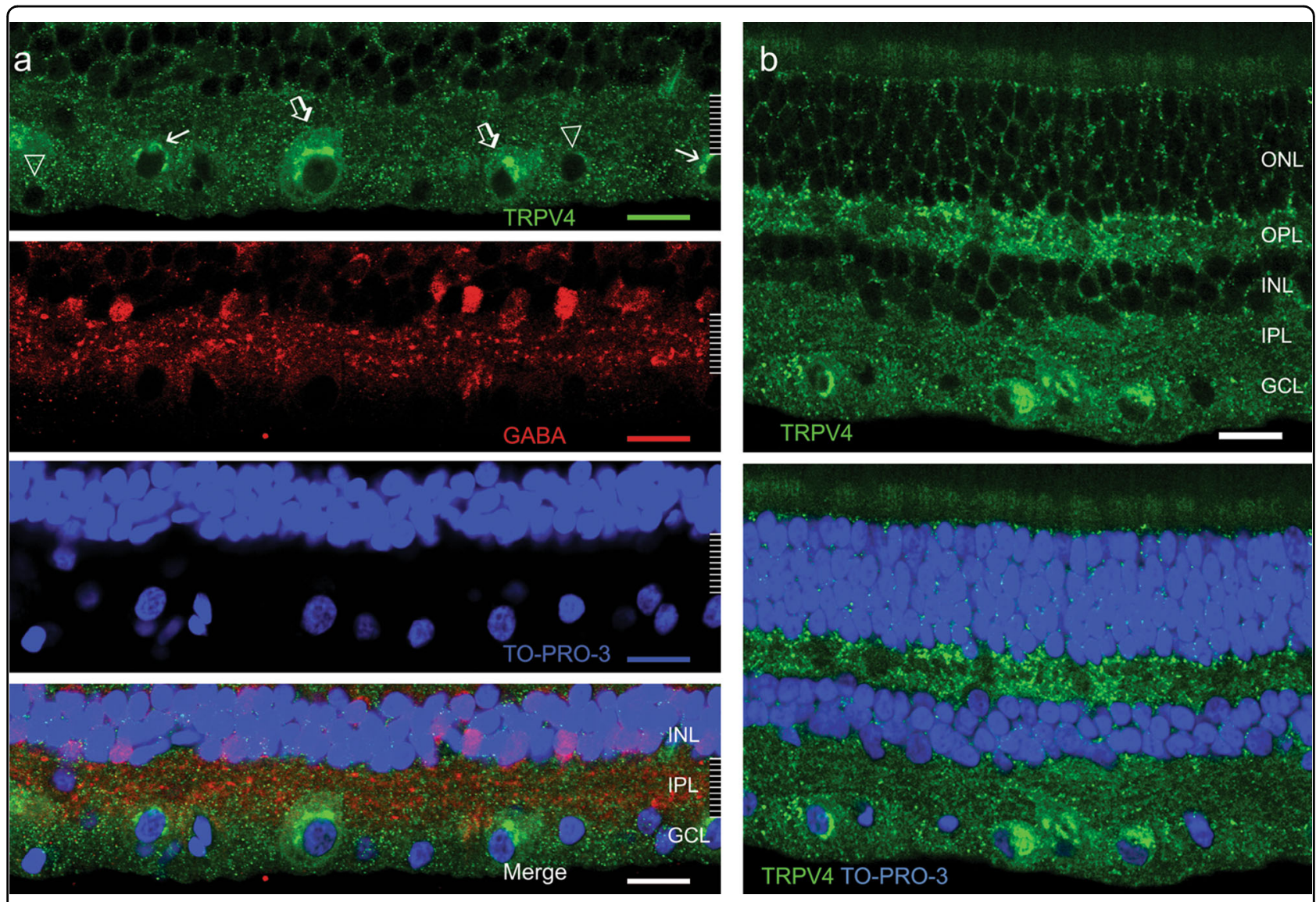

Fig. 1 TRPV4 expression in the primate retina. Confocal micrographs of retinal slices are double or triple-labeled for TRPV4 (green, LS-C135), GABA (red, a) and TO-PRO-3 (blue). TRPV4 signals appear as puncta, and large and medium RGCs (open arrow, a) in the ganglion cell layer (GCL) negative for GABA are the most intensively labeled. In these RGCs, TRPV4 puncta are larger and denser in the cytosol and absent inside the nucleus. Smaller RGCs in the GCL that are negative for GABA are moderately (arrow, a) to weakly (triangle, a) positive for TRPV4. TRPV4 signals show a higher density in the outer and inner plexiform layers (OPL and IPL, respectively, b) than in the inner and outer nuclear layers (INL and ONL, respectively). In nuclear layers, TRPV4 signals are sparse and often surround cell bodies (b). Scale bars are $20 \mu \mathrm{m}$

\section{Statistical analysis}

Data were analyzed by Sigmaplot software (v12, Systat, Point Richmond, CA), Clampfit (v10.3 and v9.2, Axon Instruments, Foster City, CA), and Microsoft Excel and presented as mean \pm s.e. Two-tail Student $t$-test was used for analyzing statistical significance between paired data groups. The $\alpha$ level to reject the null hypothesis was 0.05 . The relationship of the membrane potential (V) and the delay time (T) of $\mathrm{Na}^{+}$currents mediated by voltage-gated $\mathrm{Na}^{+}$channels $\left(\mathrm{I}_{\mathrm{Na}}\right)$ was well fit by a standard exponential function $f(V)=\sum_{i=1}^{n} T_{i} e^{-V / i}+C$. The pressure response curves were well fit by an exponential cumulative distribution function $f(P)=\sum_{i=1}^{n} R_{i}\left(1-e^{-P / i}\right)+C$, where $R$ was the amplitude of normalized responses. The histograms of pixel intensity (I) were well fit by a Gaussian function $f(I)=a e^{\left[-0.5\left(\frac{I-I_{0}}{b}\right)^{2}\right]}$, where $\mathrm{a}$ is the maximum frequency and $\mathrm{I}_{0}$ is the peak intensity. Clampfit and Sigmaplot software was used for finding the best fitting functions.

\section{Results}

TRPV4 was most intensively expressed in large- to medium-sized RGC somas

We examined TRPV4 immunoreactivity in 8 retinas with three TRPV4 antibodies. RGCs were differentiated from ACs by the absence of clear GABA and glycine immunoreactivities. TRPV4 immunoreactivity appeared as small to large puncta (Fig. 1). Small TRPV4 puncta revealed soma boundaries of some RGCs and plexiform layers, indicating the expression in the neuronal plasma membrane. Clusters of large TRPV4 puncta were observed in the cytosol of large and medium somas of RGCs $(\geq 15 \mu \mathrm{m} \text { in diameter })^{42,43}$, particularly in the perinuclear region, presumably in the rough endoplasmic reticulum where proteins are synthesized. The specificity of LS-A8583 and LS-C94498 has been previously 


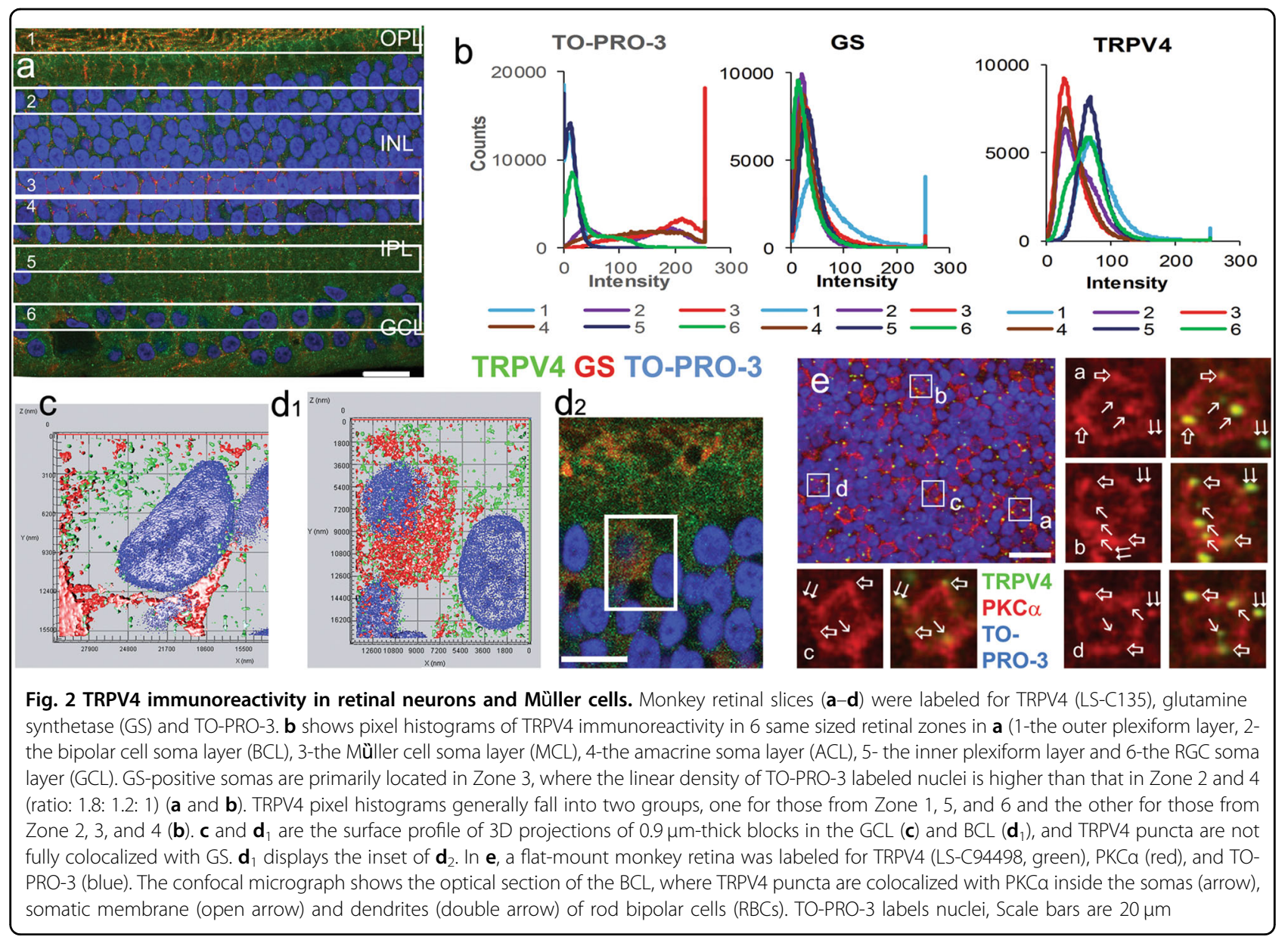

confirmed in the TRPV4 knockout mouse ${ }^{7}$. LS-C135 and LS-A8583 provided similar labeling patterns. Smaller somas in the GCL were generally more weakly labeled compared with larger ones (Fig. 1). Brightly labeled RGC somas were distributed sparsely in the retina, and their density was estimated to be $77 \pm 11$ cells $/ \mathrm{mm}^{2}(n=2$ retinal preparations) in the peripheral retina. RGC somas possessed only a few small TRPV4 immunoreactive puncta were not counted due to the low visibility.

\section{The expression of TRPV4 in other retinal layers}

The intensity of TRPV4 immunoreactivity was higher in the GCL and the inner and outer plexiform layers (IPL and OPL, respectively) compared with the inner and outer nuclear layers (INL and ONL, respectively), and TRPV4 was not fully colocalized with GS (Fig. 2). GS-labeled somas of Müller cells were primarily arranged in a layer (MCL) at $\sim 66 \%$ of the INL depth (with $0 \%$ representing the outer border) resembling previous findings ${ }^{40,44}$, and the layer was also identifiable by the higher linear density of TO-PRO-3labeled nuclei compared to that in the upper (the $\mathrm{BC}$ soma layer, $\mathrm{BCL}$ ) and the lower half (the $\mathrm{AC}$ soma layer, $\mathrm{ACL}$ ) of the INL (ratio: 1.8: 1.2: 1) (Fig. 2a, b). TRPV4 immunoreactivity was observed in Müller cells' processes in the OPL (Fig. 2a and $d_{2}$ ), somas in the INL (Fig. 2d), and end feet in the GCL (Fig. 2c), while some TRPV4 puncta in the GCL (Fig. 2c) and BCL (Fig. 2d) were not colocalized with GS. Some TRPV4 puncta were colocalized with PKC $\alpha$ in somas and dendrites of rod BCs (RBCs) (Fig. 2e). Intensity histograms of TRPV4 pixels (Fig. 2b) were well fit to a Gaussian function (see method) (all $p<0.0001$ ), consisting of either a high-intensity (OPL and IPL; $b: 17.4-24.4 ; I_{0}$ : 67.5-73.4) or a low-intensity (MCL and ACL; $b$ : 16.8-19.9; $I_{0}$ : 31.6-36.1) component or both (GCL and BCL). The GCL histogram $\left(b: 25.5 ; I_{0}: 61.7\right)$ and BCL histogram $\left(b: 27.5 ; I_{0}\right.$ : 41.8) contained both components, but the former showed higher peak intensity $I_{0}$. Histograms from the BCL, ACL, and MCL were similar, while that of the MCL showed the highest $a$ value (Fig. 2b). The data indicate that TRPV4 is expressed in neurons in the GCL and BCL.

\section{Activating TRPV4 enhanced the firing rate, sEPSC} amplitude and frequency, and the membrane excitability of parasol RGCs

For electrophysiological recordings, current responses of cells were recorded under voltage-clamp 
a

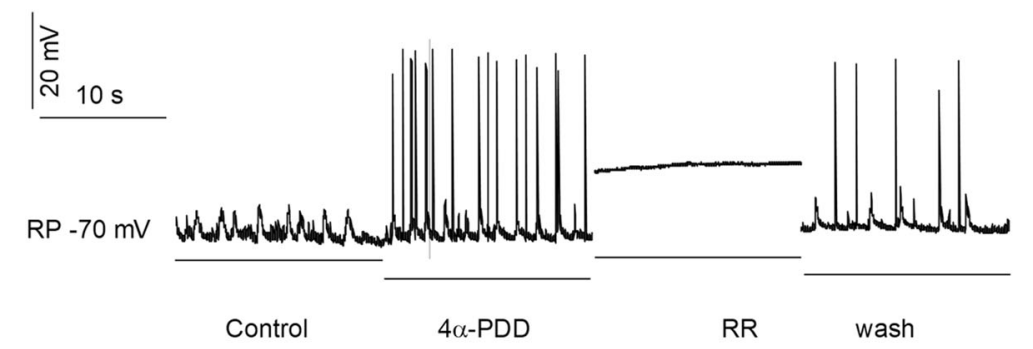

b

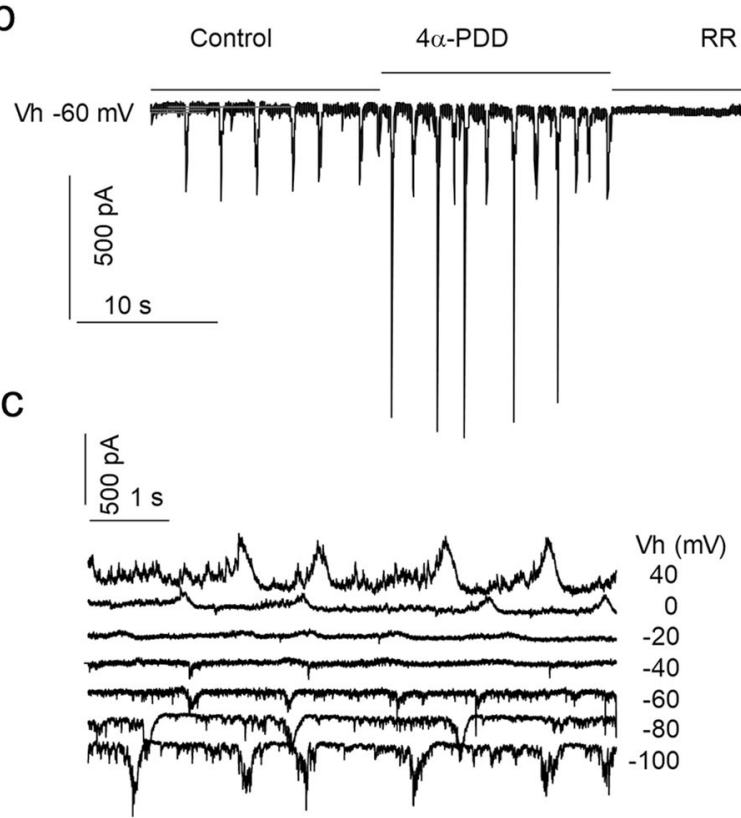

d
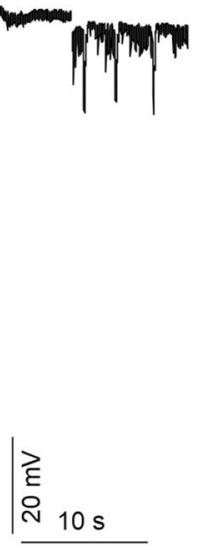

$\mathrm{RP}-70 \mathrm{mV}$ e

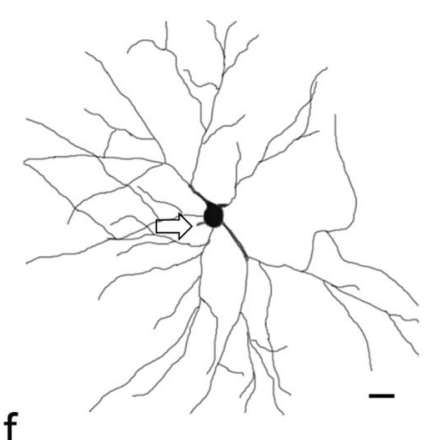

f wash
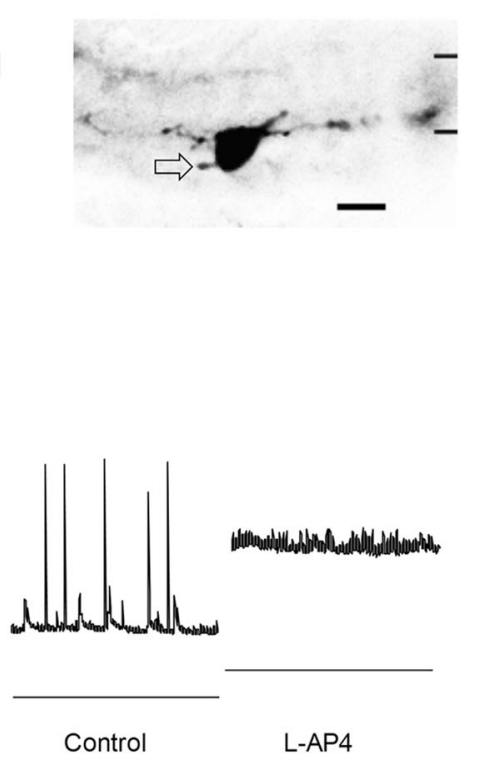

Fig. 3 The activation of TRPV4 enhances the amplitude and frequency of spontaneous excitatory postsynaptic currents (sEPSCs)in RGCs. A RGC was recorded under whole-cell current-clamp $(\mathbf{a}, \mathbf{d})$ (holding current I =0) for action potentials and voltage-clamp (b and $\mathbf{c})$ modes for spontaneous postsynaptic currents (sPSCs) from a flat mount retina. sEPSCs were recorded at the chloride equilibrium potential $\left(\mathrm{E}_{\mathrm{Cl}},-61 \mathrm{mV}\right)$. The bath application of TRPV4 agonist 4aPDD $(0.4 \mu \mathrm{M}, \mathbf{a}, \mathbf{b})$ evokes firing of action potentials $(\mathbf{a})$ and an increase in the frequency and amplitude of sEPSCs (b). These effects were reversibly abolished by a general MSC blocker ruthenium red (RR) (5 $\mu \mathrm{M})$. sPSCs (c) reverse near $-20 \mathrm{mV}$ and action potentials and spontaneous postsynaptic potentials are abolished by mGluR6 agonist L-AP4 (d), demonstrating that the activities are dominated by chemical synapses from ON bipolar cells. The cell was identified as an ON cell by neurobiotin labeling. The cell morphology revealed from the flatmount retina (e) shows a soma of $27 \mu \mathrm{m}$ in diameter and a dendritic field of $356 \times 267 \mu \mathrm{m}$. The dendrites observed from retinal slices (f) ramify around $70 \%$ of the IPL depth. In e and $\mathbf{f}$, arrows show the axon, and scale bars are $20 \mu \mathrm{m}$. Vh-holding potential; RP-resting potential

conditions, voltage responses and action potentials under current-clamp conditions, and spikes under loose patch conditions. To understand the function of retinal TRPV4, we examined the effect of TRPV4 channel modulators on RGC spontaneous action potentials and sEPSCs (Figs. 3 and 4). Recorded RGCs were filled with neurobiotin (NB) and/or Lucifer yellow (LY) during patch-clamp recording. The morphology of each recorded cell was examined with confocal microscopy first in the flat-mount retina and then in vertical slices. Parasol RGCs were identified by their morphology and physiology.
TRPV4 channel agonists $4 \alpha$ PDD $(\leq 2 \mu \mathrm{M})$ and GSK $(\leq 1 \mu \mathrm{M})$ significantly enhanced the spontaneous firing rate of action potentials (Figs. 3 and 4) and the frequency and amplitude of sEPSCs (Fig. 3) in parasol RGCs $(n=5$ cells). The frequency of events was increased $\sim 2.1$ times $(n=54$ trials) and the amplitude of sEPSCs were $\sim 2.3$ times larger ( $p<0.0001, n=19$ trials). These effects were reversibly abolished by a general MSC blocker ruthenium red (RR).

The spontaneous action potentials were abolished by mGluR6 agonist L-AP4 in ON cells (Fig. 3d). The reversal potential of spontaneous postsynaptic currents (sPSCs) 

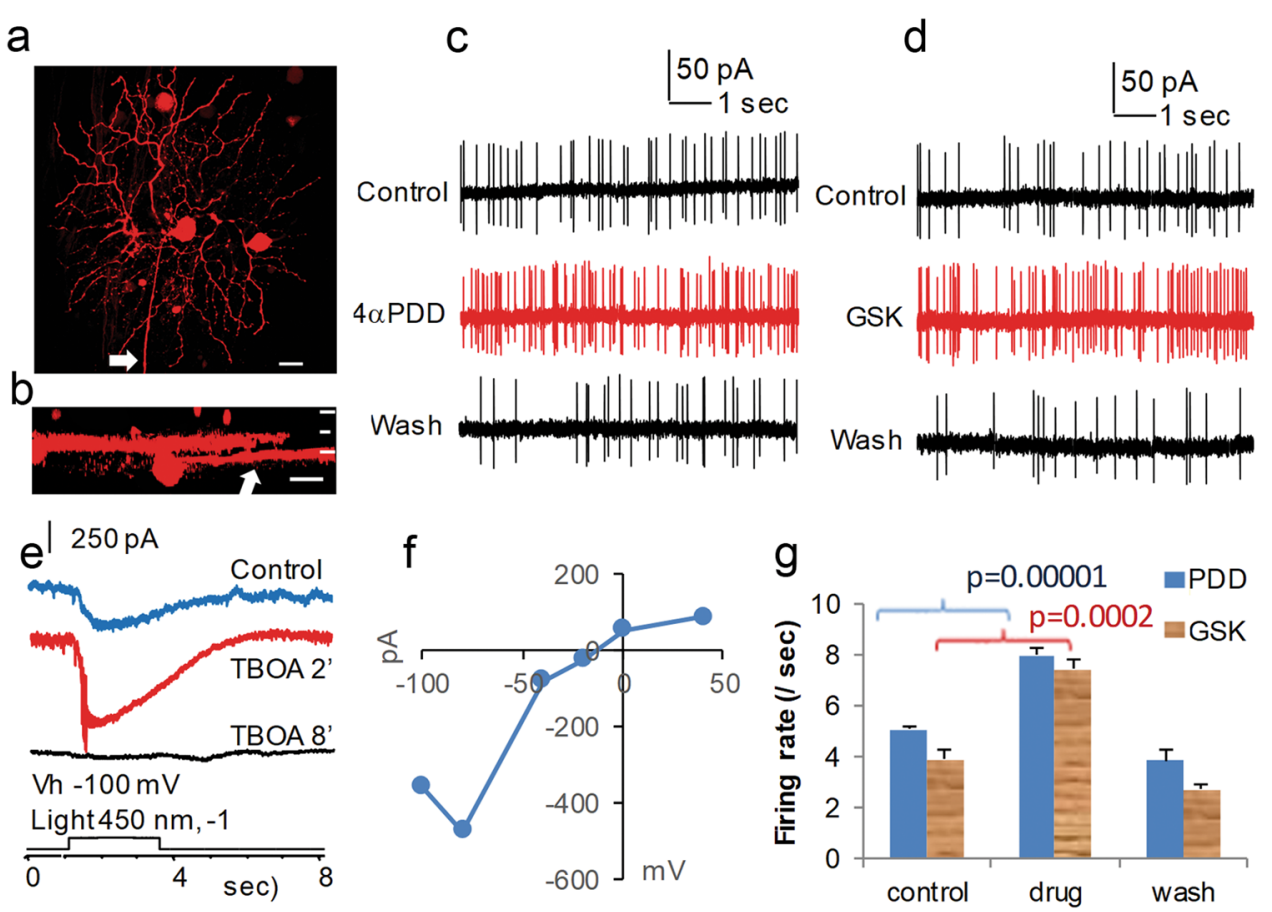

Fig. 4 Opening TRPV4 enhances the spontaneous firing in parasol ganglion cells. a to $\mathbf{f}$ show an RGC, which was recorded for action potentials under loose-patch mode (c and $\mathbf{d}$ ) and for light-evoked currents under voltage-clamp mode (e and $\mathbf{f}$ ) from a flat mount retina. The cell was filled with neurobiotin during recording. Confocal micrographs ( $\mathbf{a}$ and $\mathbf{b})$ morphologically identify the cell as an ON parasol cell. The $x-y$ view (a) and $y-z$ view (b) of the 3D reconstructed cell images reveal a soma of $25 \mu \mathrm{m}$ in diameter and a dendritic arbor of $254 \times 218 \mu \mathrm{m}$ ramified round $65 \%$ of the IPL depth. Current responses evoked by the light steps of a duration of $2.5 \mathrm{~s}$ reverse near $-15 \mathrm{mV}$ (e and $\mathbf{f}$ ) and are inward cation currents at $E_{\mathrm{Cl}}$ $(-61 \mathrm{mV})$, and the light-evoked current (e) was enhanced by $250 \mu \mathrm{M}$ TBOA (a glutamate transporter inhibitor) after 2 minutes of bath application of the drug and fully abolished after 8 minutes, which indicate that the activities are dominated by ON bipolar cell inputs. TRPV 4 agonists $4 a P D D ~ 0.4 \mu M$ (c and $\mathbf{g}$ ) and GSK $0.4 \mu \mathrm{M}$ (d and $\mathbf{g}$ ) applied in the bath show similar effects on RGCs (g), which significantly and reversibly increase the spontaneous firing rate ( $\mathbf{g}, n=5$ experiments/cells, two-tail t-test, $p<0.001$ for both drugs). In $\mathbf{a}$ and $\mathbf{b}$, the arrow shows the axon and scale bars are $20 \mu \mathrm{m}$. Vhholding potential

(Fig. 3c) and light-evoked currents (Fig. 4f) were near 0 to $-20 \mathrm{mV}$, which was closer to $\mathrm{E}_{\mathrm{C}}(0 \mathrm{mV})$ than $\mathrm{E}_{\mathrm{Cl}}$ $(-61 \mathrm{mV})$. These results support the idea that activities of parasol RGCs are dominated by chemical synapses from $\mathrm{BCs}$ instead of ACs. sEPSCs were recorded at $\mathrm{E}_{\mathrm{Cl}}$ (see Methods for details), separating the excitatory inputs (from BCs) from the inhibitory chloride currents (from $A C s)^{29,31}$. In the CNS, it has been known for many years that the frequency of spontaneous events is due to presynaptic release properties ${ }^{45,46}$. Taken together, the data indicate that opening TRPV4 channels enhances spontaneous excitatory inputs from BCs to RGCs.

We further studied the effect of TRPV4 agonists on $\mathrm{Na}^{+}$ currents $\left(\mathrm{I}_{\mathrm{Na}}\right)$ in parasol RGCs mediated by voltage-gated $\mathrm{Na}^{+}$channels (Nav) (Fig. 5). $\mathrm{I}_{\mathrm{Na}}$ was evoked under voltage-clamp conditions by depolarizing RGC membrane potentials from -110 or $-70 \mathrm{mV}$ with a step of $8-15 \mathrm{mV}$, which would not be significantly affected by BC and AC synapses. $\mathrm{I}_{\mathrm{Na}}$ was activated at $\sim-50 \mathrm{mV}(n=5$ cells $)$, consistent with voltage-gated $\mathrm{Na}$ channels well documented in previous literature ${ }^{4,48}$. The peak amplitude, as well as the delay time of $\mathrm{I}_{\mathrm{Na}}$, i.e. the time between the beginning of stimuli to the beginning of evoked inward $\mathrm{I}_{\mathrm{Na}}$, was examined before and during bath application of drugs for 1-3 min. The data showed that the drug did not clearly alter the activation curve or the peak amplitude of $\mathrm{I}_{\mathrm{Na}}$, but it shortened the delay time of $\mathrm{I}_{\mathrm{Na}}$ evoked by all depolarizing pulses above the threshold $(p<0.05)$, which indicate that activating TRPV4 increases RGC membrane excitability.

The pressure and temperature sensitivity of bipolar cells

In retinal slices, we recorded pressure-induced responses in BCs with vertical oval somas located in the distal half of the inner nuclear layer (Fig. 6). The cells were filled with $\mathrm{LY}$ and/or NB during recording and identified as bipolar cells by a typical bipolar morphology with dendrites extending into the OPL and an axon descending to the IPL (Fig. 6). Pressure steps of a duration of 200-3000 ms evoked transient responses in BCs. Positive pressure applied to the intracellular side activated a cation conductance which reversed at $\sim-10 \mathrm{mV}$, and releasing 

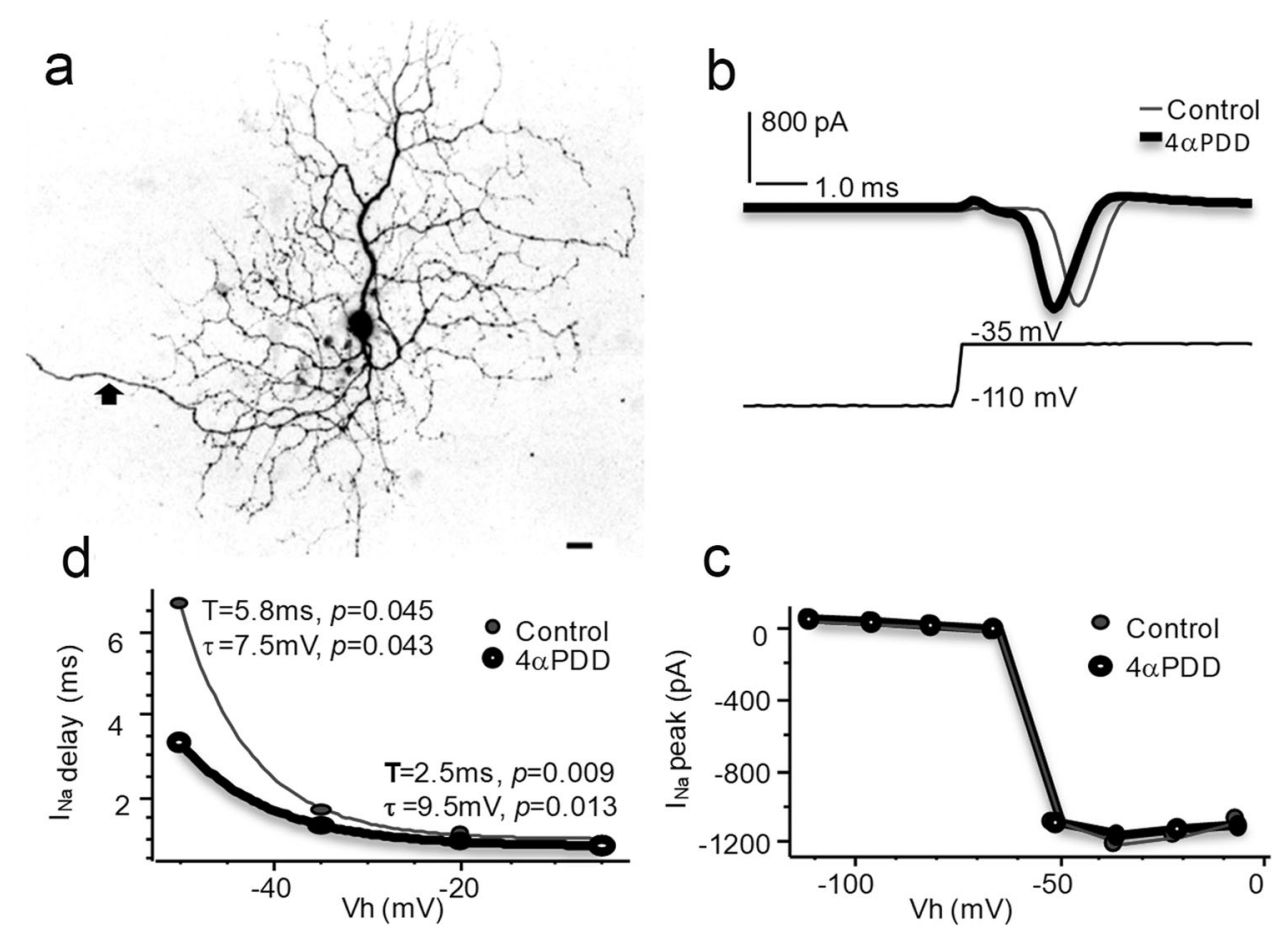

C

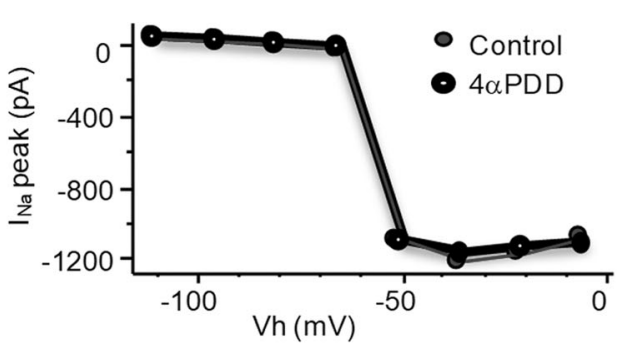

Fig. 5 Activating TRPV4 enhances membrane excitability of parasol ganglion cells. Na currents $\left(\left.\right|_{N a}\right)$ mediated by voltage-gated Na channels were recorded under whole-cell voltage-clamp mode from flat mount retinas. Electric pulses were used to hold the membrane potential from a baseline level of $-110 \mathrm{mV}(\mathbf{b}$ and $\mathbf{c})$ or $-70 \mathrm{mV}(\mathbf{d})$ to a series of $\mathrm{Vh}$. The $\mathrm{I}_{\mathrm{Na}}$ is activated at $\mathrm{Vh} \approx-50 \mathrm{mV}$ (c). The application of TRPV4 agonist 4aPDD $1 \mu \mathrm{M}$ in the bath does not clearly alter the activation curve (c) or peak amplitude of $I_{\mathrm{Na}}(\mathbf{b})$, while the delay time (T) of $I_{\mathrm{Na}}$ is shortened for all suprathreshold stimuli $(\mathbf{d})$. The relationship of $T$ and $V h$ is significantly altered ( $p<0.05$ for both $T$ and $T$ ) (For definitions of $\tau$ see methods). In $\mathbf{a}$, the arrow depicts the axon, and the scale bar is $20 \mu \mathrm{m}$. The chloride equilibrium potential is $-61 \mathrm{mV}$. Vh-holding potential

the pressure reduced the cation conductance. Negative pressures applied to the intracellular side induced responses of opposite polarities but the same reversal potential. The pressure-response curve was well fit by an exponential cumulative distribution function and $\tau$ was $34 \mathrm{mmHg}$ (range: $15-46 \mathrm{mmHg}$ ) (For the definition of $\mathrm{\tau}$, see Methods). The mean pressure to evoke the halfmaximal response was $\sim 18 \mathrm{mmHg}$ (range: $10-23 \mathrm{mmHg}$ ). Upon heating the bath from $24^{\circ} \mathrm{C}$ to $30^{\circ} \mathrm{C}$, the amplitude of the pressure-induced responses increased by $40-100 \%$.

\section{Discussion}

\section{Parasol RGCs and other large RGCs in the primate retina intensively express TRPV4}

We identified parasol RGCs by their soma size and dendritic morphology ${ }^{49}$. We also distinguished RGCs from ACs by their axons, large somas and the absence of the immunoreactivities to GABA and glycine. RGCs in the mouse $^{7}$, rat $^{25}$ and porcine ${ }^{8}$ retinas have been reported to express TRPV4, and our data are consistent with these previous studies. $4 \alpha \mathrm{PDD}$ and GSK have been used to identify TRPV4 in the retina ${ }^{7}$ and elsewhere ${ }^{15}$. TRPV4 is a pressure-sensitive warm sensor, and our results showed that $\mathrm{BCs}$ responded to both pressure and warm temperature. Our immunocytochemical results, combined with others' studies ${ }^{7,8,25}$ and our physiological data, support that TRPV4 was properly identified and it was intensively expressed in large RGCs.

\section{Opening TRPV4 channels excites both BCs and RGCs}

The opening of TRPV4 induced by pharmacological agonists and hypotonicity is known to depolarize the neuronal membrane and increase the spontaneous firing rate in mouse $\mathrm{RGCs}^{7}$, but it has been unclear whether the effect is related to BCs. The IPL and OPL in mammalian retinas $^{7,8}$ have been previously shown to express TRPV4, yet BCs have not been known to express TRPV4 before. Our results showed that RGCs, plexiform layers, and BCs express TRPV4. Additionally, this study is the first to show that opening TRPV4 enhances sEPSC frequency in RGCs and that BCs are mechanosensitive. The pressure for evoking the half-maximal response in BCs reported in this study is comparable to that for mechano-gated channels in other studies ${ }^{36}$.

Müller cells express TRPV $4^{50}$ but make no synapses with retinal neurons ${ }^{23}$. They express the glutamate transporter $\mathrm{GLAST}^{51}$ to modulate neuronal activities. Glutamate transportation relies on the energy stored in 

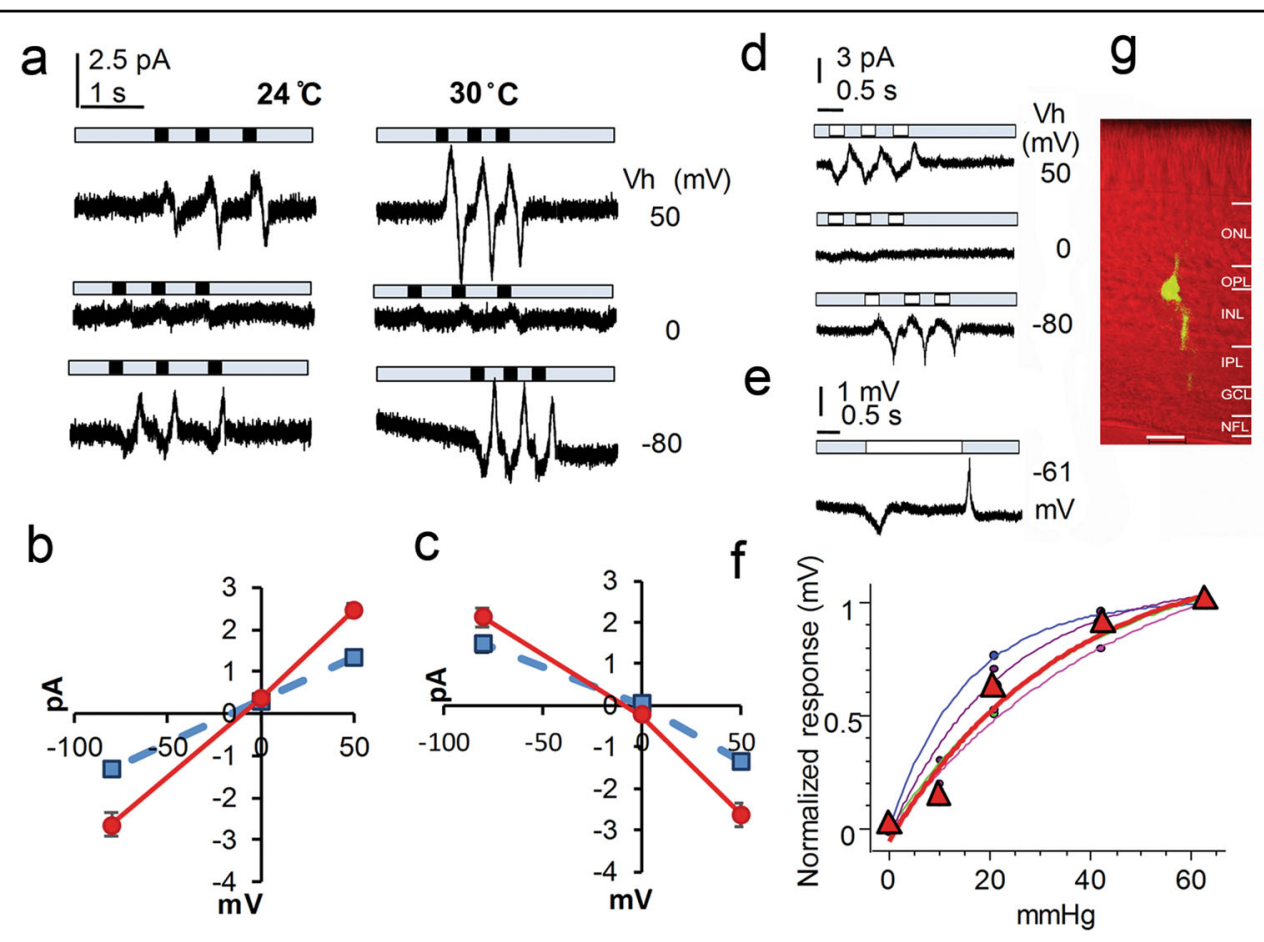

Fig. 6 Pressure and temperature sensitivity of bipolar cells. The internal solution in the recording pipette contained $\mathrm{Cs}^{+}$to block $\mathrm{K}^{+}$channels. a shows current responses to brief pressure steps of $42 \mathrm{mmHg}$ (black rectangles) applied to the intracellular side at holding potentials (Vh) of $-80,0$ and $50 \mathrm{mV}$. The onset of pressure steps activates a cation conductance that reversed near $-10 \mathrm{mV}(\mathbf{b})$, and the offset reduces the cation conductance (c). Currents elicited by the positive (a) and negative ( $\mathbf{d},-42 \mathrm{mmHg}$, white rectangles) pressure steps show opposite polarities but the same reversal potential. Pressure-induced responses were largely enhanced upon heating from $24{ }^{\circ} \mathrm{C}$ ( $\mathbf{b}$ and $\mathbf{c}$, blue squares and dashed lines) to $30^{\circ} \mathrm{C}(\mathbf{b}$ and $\mathbf{c}$, red dots and solid lines) ( $p<0.001, n=6$ experiments/cells). Negative pressure of longer durations (e, $-42 \mathrm{mmHg}$, white rectangles) applied to the intracellular side elicits transient voltage responses. The pressure - normalized response curves are well fit by an exponential cumulative distribution function (f $\mathbf{f}$, dots and fine lines) ( $n=4$ experiments/cells), and the mean is displayed in red (triangles and the thick line). $\mathbf{g}$-confocal image of a recorded bipolar cell filled with Lucifer yellow (yellow) and presented against a Nomarski view (red) of the retinal slice. The scale bar in $\mathbf{g}$ is $20 \mu \mathrm{m}$

the $\mathrm{Na}^{+}$electrochemical gradient, and opening TRPV4 in cells causes $\mathrm{Na}^{+}$influxes ${ }^{14,26}$. Therefore, opening TRPV4 in Müller cells would reduce glutamate removal near synapses. However, reducing glutamate removal by either acutely inhibiting ${ }^{52}$ or knocking out GLAST ${ }^{53}$ was found to reduce the ERG b-wave instead of exciting BCs. Data from $\mathrm{BC}$ /putative RGC pairs showed that reducing glutamate uptake in Müller cells did not alter the amplitude, time course, or frequency of sEPSCs in RGCs, though evoked EPSCs were elongated ${ }^{54}$. Recent studies further confirmed key distinctions between the synaptic vesicle fusion machineries that perform spontaneous versus evoked neurotransmitter release ${ }^{46}$. Moreover, mechanically stimulating Müller cells was found to inhibit RGCs ${ }^{55}$. Therefore, we feel that TRPV4 in Müller cells is not accountable for our physiological results in RGCs and BCs.

We applied pressure stimulation in individual BC somas. The mechanical sensitivity is, therefore, primarily attributed to ion channels located in BCs. Although multiple mechanically sensitive channels are thermosensitive, TRPV4 has unique thermosensitivity ${ }^{14,15}$ and it has not been found in photoreceptors or $\mathrm{HCs}^{7,8,25,26}$.
Therefore, our physiological and morphological results together indicate that $\mathrm{BCs}$ are mechanically sensitive and express TRPV4. Our data, however, did not fully exclude other MSCs in BCs from contributing to the BC's mechanical sensitivity. In the CNS, the frequency of spontaneous events is due to presynaptic release properties while the amplitude and shape of the response are largely attributed to postsynaptic changes in ionotropic receptor responses ${ }^{45,46}$. Thus, we think that the effect of $4 \mathrm{aPDD}$ on the frequency of sEPSCs in RGCs is accounted for by TRPV4 in BCs; and the effect of 4aPDD on the amplitude of sEPSCs in RGCs is primarily attributed to TRPV4 in RGCs. Further studies on isolated cells combined with pharmacological channel antagonists will likely better map the expression of mechanically sensitive channels in subtypes of retinal neurons.

In the peripheral nervous system, a few reports have shown that $\mathrm{Na}^{+}$currents are sensitive to thermal and mechanical stimuli ${ }^{56-58}$, and our data are consistent with these previous reports. Additionally, we further showed that opening TRPV4 in RGCs enhanced the membrane excitability. 


\section{TRPV4 and BCs likely play some roles in glaucoma}

Glaucoma retinopathy is highly correlated with IOP elevation and how RGCs are damaged is not clear ${ }^{1}$. Our results show that RGCs and BCs express TRPV4, opening TRPV4 excites RGCs, and BCs are mechanically sensitive. The results, in line with others' findings ${ }^{7,8}$, suggest that TRPV4 and BCs may play some roles in glaucoma.

Glutamate excitotoxicity is an important mechanism underlying neuronal degenerative diseases in the CNS including glaucoma ${ }^{59}$, but triggers for excessive glutamate release in glaucoma have not yet been identified. TRPV4mediated $\mathrm{Ca}^{2+}$ and $\mathrm{Na}^{+}$influxes can possibly elicit glutamate release from $\mathrm{BCs}$ to $\mathrm{RGCs}^{23}$. This study is the first to reveal functional TRPV4 channels and mechanical sensitivity in BCs, providing a novel potential route for IOP elevation to enhance glutamate release.

RGCs receive convergent inputs from $\mathrm{BCs}$ and the convergence is more intensive in the peripheral retina than in the central retina ${ }^{60}$. Rods are the dominant photoreceptor types in the vast peripheral retinal region and rod BCs feed excitatory signals to RGCs. Therefore, we deduce that the extensive convergence of $\mathrm{BC}$ inputs would allow the low density of TRPV4 and pressureinduced small responses in $\mathrm{BCs}$ to more dramatically affect the function of RGCs in the mid-peripheral and peripheral retina than those in the central retina. Pressure-induced transient responses in BCs also suggest that TRPV4 could possibly respond to IOP fluctuation ${ }^{11}$. Our data together indicate that TRPV4 plays important roles in primate retinal BCs and RGCs, and RGCs and $\mathrm{BCs}$ are both mechanosensitive neurons.

\section{Acknowledgements}

We thank Dr. David W Marshak at the University of Texas Health Science Center in Houston McGovern Medical School for sharing some primate retinas with us. Applicable Funding Source Research to Prevent Blindness (RPB) - n/a [Departmental] Knights Templar Eye Foundation (Knights Templar Eye Foundation, Inc.) - n/a [Pang] U.S. Department of Health \& Human Services | NIH | National Eye Institute (NEI) - Core EY 02520 [Departmental] U.S. Department of Health \& Human Services | NIH | National Eye Institute (NEI) - EY004446 [Wu] U.S. Department of Health \& Human Services | NIH | National Eye Institute (NEI) EY019908 [Wu]Retinal research foundation Inc. (RRF) (Houston) [Wu].

\section{Conflict of interest}

The authors declare that they have no conflict of interest.

\section{Publisher's note}

Springer Nature remains neutral with regard to jurisdictional claims in published maps and institutional affiliations.

Received: 24 January 2018 Accepted: 25 March 2019

Published online: 07 May 2019

\section{References}

1. Quigley, H. A. Glaucoma. Lancet 377, 1367-1377 (2011).

2. Caprioli, J. \& Coleman, A. L. Intraocular pressure fluctuation a risk factor for visual field progression at low intraocular pressures in the advanced glaucoma intervention study. Ophthalmology 115, 1123-1129 (2008).
3. Asrani, S. et al. Large diurnal fluctuations in intraocular pressure are an independent risk factor in patients with glaucoma. J. Glaucoma 9, 134-142 (2000).

4. Liu, C. \& Montell, C. Forcing open TRP channels: mechanical gating as a unifying activation mechanism. Biochem. Biophys. Res. Commun. 460, 22-25 (2015).

5. Tan, J. C., Kalapesi, F. B. \& Coroneo, M. T. Mechanosensitivity and the eye: cells coping with the pressure. Br. J. Ophthalmol. 90, 383-388 (2006).

6. Krizaj, D. Polymodal sensory integration in retinal ganglion cells. Adv. Exp. Med. Biol. 854, 693-698 (2016).

7. Ryskamp, D. A. et al. The polymodal ion channel transient receptor potential vanilloid 4 modulates calcium flux, spiking rate, and apoptosis of mouse retinal ganglion cells. J. Neurosci. 31, 7089-7101 (2011).

8. Taylor, L., Arner, K. \& Ghosh, F. Specific inhibition of TRPV4 enhances retinal ganglion cell survival in adult porcine retinal explants. Exp. Eye Res. 154, 10-21 (2016).

9. Auer-Grumbach, M. et al. Alterations in the ankyrin domain of TRPV4 cause congenital distal SMA, scapuloperoneal SMA and HMSN2C. Nat. Genet. 42, 160-164 (2010).

10. Hamill, O. P. \& McBride, D. W. Jr. Rapid adaptation of single mechanosensitive channels in Xenopus oocytes. Proc. Natl Acad. Sci. USA 89, 7462-7466 (1992).

11. Downs, J. C. et al. 24-hour IOP telemetry in the nonhuman primate: implant system performance and initial characterization of IOP at multiple timescales. Invest. Ophthalmol. Vis. Sci. 52, 7365-7375 (2011).

12. Sigal, I. A., Flanagan, J. G., Tertinegg, I. \& Ethier, C. R. Finite element modeling of optic nerve head biomechanics. Invest Ophthalmol. Vis. Sci. 45, 4378-4387 (2004).

13. Shin, D. H., Bielik, M., Hong, Y. J., Briggs, K. S. \& Shi, D. X. Reversal of glaucomatous optic disc cupping in adult patients. Arch. Ophthalmol. 107, 1599-1603 (1989).

14. Montell, C. The TRP superfamily of cation channels. Sci STKE. 2005, re3 (2005).

15. Nilius, B. \& Szallasi, A. Transient receptor potential channels as drug targets: from the science of basic research to the art of medicine. Pharmacol. Rev. $\mathbf{6 6}$, 676-814 (2014)

16. Clapham, D. E. SnapShot: mammalian TRP channels. Cell. 129, 220 (2007).

17. Suzuki, M., Mizuno, A., Kodaira, K. \& Imai, M. Impaired pressure sensation in mice lacking TRPV4. J. Biol. Chem. 278, 22664-22668 (2003).

18. Liedtke, W. et al. Vanilloid receptor-related osmotically activated channel (VROAC), a candidate vertebrate osmoreceptor. Cel/103, 525-535 (2000).

19. Fernández-Carvajal A., Fernández-Ballester G., González-Muñiz R., FerrerMontiel A. Chapter 2 Pharmacology of TRP Channels. In: Madrid R., Bacigalupo J. (eds), TRP Channels in Sensory Transduction Alicante, Spain: Springer International Publishing Switzerland; 2015:41-50.

20. O'Neil, R. G. \& Heller, S. The mechanosensitive nature of TRPV channels. Pflugers Arch. 451, 193-203 (2005).

21. Agostinone, J. \& Di, P. A. Retinal ganglion cell dendrite pathology and synapse loss: Implications for glaucoma. Prog. Brain Res. 220, 199-216 (2015).

22. Pang, J. J., Frankfort, B. J., Gross, R. L. \& Wu, S. M. Elevated intraocular pressure decreases response sensitivity of inner retinal neurons in experimental glaucoma mice. Proc. Natl Acad. Sci. USA 112, 2593-2598 (2015).

23. Dowling, J. E. The Retina an approachable part of the brain. (Harvard University Press/Belknap Press, Cambridge, 2012).

24. Frankfort, B. J. et al. Elevated intraocular pressure causes inner retinal dysfunction before cell loss in a mouse model of experimental glaucoma. Invest. Ophthalmol. Vis. Sci. 54, 762-770 (2013).

25. Sappington, R. M. et al. Activation of transient receptor potential vanilloid-1 (TRPV1) influences how retinal ganglion cell neurons respond to pressurerelated stress. Channels 9, 102-113 (2015).

26. Jo, A. O. et al. TRPV4 and AQP4 channels synergistically regulate cell volume and calcium homeostasis in retinal muller glia. J. Neurosci. 35, 13525-13537 (2015).

27. Bleckert, A., Schwartz, G. W., Turner, M. H., Rieke, F. \& Wong, R. O. Visual space is represented by nonmatching topographies of distinct mouse retinal ganglion cell types. Curr. Biol. 24, 310-315 (2014).

28. Jacoby, R., Stafford, D., Kouyama, N. \& Marshak, D. Synaptic inputs to ON parasol ganglion cells in the primate retina. J. Neurosci. 16, 8041-8056 (1996).

29. Gao, F. \& Wu, S. M. Multiple types of spontaneous excitatory synaptic currents in salamander retinal ganglion cells. Brain Res. 821, 487-502 (1999).

30. Gao, F. \& Wu, S. M. Characterization of spontaneous inhibitory synaptic currents in salamander retinal ganglion cells. J. Neurophysiol. 80, 1752-1764 (1998). 
31. Pang, J. J., Gao, F. \& Wu, S. M. Relative contributions of bipolar cell and amacrine cell inputs to light responses of ON, OFF and ON-OFF retina ganglion cells. Vision Res. 42, 19-27 (2002).

32. Pang, J. J., Gao, F. \& Wu, S. M. Light-evoked excitatory and inhibitory synaptic inputs to ON and OFF alpha ganglion cells in the mouse retina. J. Neurosci. 23, 6063-6073 (2003).

33. Pang, J. J. et al. Direct rod input to cone BCs and direct cone input to rod BCs challenge the traditional view of mammalian BC circuitry. Proc. Natl Acad. Sci. USA 107, 395-400 (2010).

34. Vriens, J., Appendino, G. \& Nilius, B. Pharmacology of vanilloid transient receptor potential cation channels. Mol. Pharmacol. 75, 1262-1279 (2009).

35. Guha, A., Barrow, R. M. \& Balachandar, R. An experimental and numerical study of water jet cleaning process. J. Mater. Process. Technol. 211, 610-618 (2011).

36. Enyedi, P. \& Czirjak, G. Molecular background of leak K+ currents: two-pore domain potassium channels. Physiol. Rev. 90, 559-605 (2010).

37. Zhang, J., Yang, Z. \& Wu, S. M. Immuocytochemical analysis of spatial organization of photoreceptors and amacrine and ganglion cells in the tiger salamander retina. Vis. Neurosci. 21, 157-166 (2004).

38. Pow, D. V., Wright, L. L. \& Vaney, D. I. The immunocytochemical detection of amino-acid neurotransmitters in paraformaldehyde-fixed tissues. J. Neurosci. Methods 56, 115-123 (1995).

39. Pang, J. J., Paul, D. L. \& Wu, S. M. Survey on amacrine cells coupling to retrograde-identified ganglion cells in the mouse retina. Invest. Ophthalmol. Vis. Sci. 54, 5151-5162 (2013).

40. Pang, J. J. \& Wu, S. M. Morphology and immunoreactivity of retrogradely double-labeled ganglion cells in the mouse retina. Invest. Ophthalmol. Vis. Sci. 52, 4886-4896 (2011).

41. Pang, J. J., Gao, F. \& Wu, S. M. Light responses and morphology of bNOSimmunoreactive neurons in the mouse retina. J. Comp. Neurol. 518, 2456-2474 (2010).

42. Weber, A. J., Kaufman, P. L. \& Hubbard, W. C. Morphology of single ganglion cells in the glaucomatous primate retina. Invest. Ophthalmol. Vis. Sci. 39, 2304-2320 (1998).

43. Moritoh, S., Komatsu, Y., Yamamori, T. \& Koizumi, A. Diversity of retinal ganglion cells identified by transient GFP transfection in organotypic tissue culture of adult marmoset monkey retina. PLoS ONE 8, e54667 (2013).

44. Bouskila, J., Javadi, P., Casanova, C., Ptito, M. \& Bouchard, J. F. Muller cells express the cannabinoid CB2 receptor in the vervet monkey retina. J. Comp. Neurol. 521, 2399-2415 (2013).
45. Scarnati, M. S., Kataria, R., Biswas, M. \& Paradiso, K. G. Active presynaptic ribosomes in the mammalian brain, and altered transmitter release after protein synthesis inhibition. Elife. 7, e36697 (2018).

46. Kavalali, E. T. The mechanisms and functions of spontaneous neurotransmitter release. Nat. Rev. Neurosci. 16, 5-16 (2015).

47. Raman, I. M. \& Bean, B. P. Resurgent sodium current and action potential formation in dissociated cerebellar Purkinje neurons. J. Neurosci. 17, 4517-4526 (1997).

48. Fohlmeister, J. F., Cohen, E. D. \& Newman, E. A. Mechanisms and distribution of ion channels in retinal ganglion cells: using temperature as an independent variable. J. Neurophysiol. 103, 1357-1374 (2010).

49. Dacey, D. M. \& Packer, O. S. Colour coding in the primate retina: diverse cell types and cone-specific circuitry. Curr. Opin. Neurobiol. 13, 421-427 (2003).

50. Netti, $V$. et al. TRPV4 contributes to resting membrane potential in retinal muller cells: implications in cell volume regulation. J. Cell Biochem. 118, 2302-2313 (2017)

51. Bringmann, A. et al. Muller cells in the healthy and diseased retina. Prog. Retin Eye Res. 25, 397-424 (2006).

52. Tse, D. Y., Chung, I. \& Wu, S. M. Pharmacological inhibitions of glutamate transporters EAAT1 and EAAT2 compromise glutamate transport in photoreceptor to ON-bipolar cell synapses. Vis. Res. 103, 49-62 (2014).

53. Harada, T. et al. Functions of the two glutamate transporters GLAST and GLT-1 in the retina. Proc. Natl Acad. Sci. USA 95, 4663-4666 (1998).

54. Matsui, K, Hosoi, N. \& Tachibana, M. Active role of glutamate uptake in the synaptic transmission from retinal nonspiking neurons. J. Neurosci. 19, 6755-6766 (1999)

55. Newman, E. A. A dialogue between glia and neurons in the retina: modulation of neuronal excitability. Neuron Glia Biol. 1, 245-252 (2004).

56. Kimura, J. E. \& Meves, $\mathrm{H}$. The effect of temperature on the asymmetrical charge movement in squid giant axons. J. Physiol. 289, 479-500 (1979).

57. Morris, C. E. \& Juranka, P. F. Nav channel mechanosensitivity: activation and inactivation accelerate reversibly with stretch. Biophys. J. 93, 822-833 (2007).

58. Collins, C. A. \& Rojas, E. Temperature dependence of the sodium channe gating kinetics in the node of Ranvier. Q. J. Exp. Physiol. 67, 41-55 (1982).

59. Hare, W. A. \& Wheeler, L. Experimental glutamatergic excitotoxicity in rabbit retinal ganglion cells: block by memantine. Invest Ophthalmol. Vis. Sci. 50, 2940-2948 (2009)

60. Silveira, L. C. et al. Morphology and physiology of primate M- and P-cells. Prog Brain Res. 144, 21-46 (2004). 